\title{
Factors Associated with Overweight and Obesity in the Schools of Parakou in 2017
}

\author{
J. Agossou1 ${ }^{*}$, A. Noudamadjo1, J. D. Adédémy¹, F. Mohamed Agbeille1, M. G. Kpanidja1, \\ F. Alihonou' ${ }^{2}$, R. Houffon', R. Ahodègnon'1, B. Ayivi²
}

\begin{abstract}
${ }^{1}$ Mother \& Child Department, Faculty of Medicine, University of Parakou; and Pediatric Unit of the Borgou/Alibori Regional University Teaching Hospital, Parakou, Benin

${ }^{2}$ Mother \& Child Department, Faculty of Health Sciences, University of Abomey-Calavi; and Pediatrics \& Medical Genetic Clinic, Hubert K Maga National University Teaching Hospital (CNHU-HKM) of Cotonou, Parakou, Benin

Email: *agossoujoseph@gmail.com
\end{abstract}

How to cite this paper: Agossou, J., Noudamadjo, A., Adédémy, J.D., Agbeille, F.M., Kpanidja, M.G., Alihonou, F., Houffon, R., Ahodègnon, R. and Ayivi, B. (2020) Factors Associated with Overweight and Obesity in the Schools of Parakou in 2017. Open Journal of Pediatrics, 10, 65-74.

https://doi.org/10.4236/ojped.2020.101005

Received: November 11, 2019

Accepted: January 17, 2020

Published: January 20, 2020

Copyright $\odot 2020$ by author(s) and Scientific Research Publishing Inc. This work is licensed under the Creative Commons Attribution International License (CC BY 4.0).

http://creativecommons.org/licenses/by/4.0/

\begin{abstract}
Introduction: The dietary changes and the new lifestyles which occurred in low-income countries like Benin resulted in a nutritional transition with its burden of overweight and obesity among the child and adolescent population who is still suffering from undernutrition. This study aimed to identify the factors associated with overweight and obesity in the schools of Parakou in 2017. Patients and Methods: This research work is a cross-sectional descriptive and analytic study carried out from May to June 2017 in the state-owned and private high/secondary schools of Parakou. It focused on a representative sample of 730 high school students randomly selected according to the WHO two-stage cluster sampling technique. The weight and size of each of the students included in the study were measured; and then their body mass index (BMI) was calculated. The data related to respondents' dietary pattern and lifestyle were collected. Those data were processed using the software Epi Info version 7.2.1. The prevalence ratio (PR) was used to measure associations with their confidence interval and the difference was considered significant when $p<05$. Findings: In total, 730 students were involved in the study, including 377 male i.e. a ratio of 1.1. Prevalence of overweight/obesity was estimated at $16.2 \%$ including $12.5 \%$ of overweight and $3.7 \%$ of obesity. The factors associated with overweight and obesity were female sex, excessive intake of sugar-sweetened beverages and drinks, low level of physical activity and family history of obesity. Conclusion: A behavior change regarding the different contributing factors is necessary to reverse the trends in overweight and obesity prevalence in the high/secondary schools in the District of Parakou.
\end{abstract}


Keywords

Associated Factors, Overweight and Obesity, Schools, Benin

\section{Introduction}

Malnutrition represents a public health concern in the world and particularly in developing countries like Benin [1]. There are two forms of malnutrition, namely undernutrition understood as shortage or deficit; and overweight/obesity understood as excess. Some authors consider as double burden of malnutrition the coexistence of those two phenomena (undernutrition and obesity). That double burden of malnutrition would be the outcome of nutritional transition in poor countries [2]. In industrialized countries, it is acknowledged for more than three decades that the prevalence of overweight and obesity among children and adolescents is growing exponentially and would be associated with their lifestyle and feeding behaviors [3]. While in low-income countries undernutrition-related problems are not yet solved, the other side of malnutrition arises surprisingly, insidiously and persistently; it is overweight and obesity among children and adolescents as shown in the literature [4] [5] [6] [7]. The purpose of this study was to identify the factors associated with overweight and obesity in the general and vocational high/secondary schools of the District of Parakou in 2017.

\section{Material and Methods}

This research work is a cross-sectional descriptive and analytical study carried out from May to June 2017 in the state-owned and private secondary/high schools of Parakou. The study population consisted of students of government-owned and private secondary schools who were present on the day of data collection and who gave their free and informed consent. The survey was conducted based on cluster random sampling according to the WHO technique; one secondary school was considered as sampling unit. Sample size was calculated using the formula of Schwartz [8] and was equal to 720 students [9]. The tools used to collect data were SECA mechanical scales, SHORR height gauge and the questionnaire for direct interview with students. The dependent variables were overweight and obesity. The independent variables were sociodemographic, socioeconomic, anthropometric, genetic (history of family obesity) and behavioral (dietary pattern and lifestyle).

Parents' socioeconomic status was defined according to types of habitat, possession or not of automotive equipment and possession or not of electrical household equipment. Each parameter was graded from 0 to 3. A score lower than or equal to 4 meant a low level. It was considered as average when it was between 5 and 10. It was high when the score was between 11 and 13. It was very high when the score was above 13.

The body mass index (BMI) which is weight in $\mathrm{kg}$ divided by square of the size expressed in meter was calculated and referred to the WHO growth chart 
using the Anthropometric calculator software among students under 19 years of age. For instance, students whose BMI was below the 3rd percentile were low birth weight; those whose BMI was between the 3rd and 85th percentile were normal; the ones whose BMI was between the 85th and 97th percentile were with overweight and the ones whose BMI was above the 97th percentile were obese [10]. To assess the weight status of students aged 19 years and above, we used the data defined by the International Obesity Task Force (IOTF). For instance, students were qualified as low birth weight when BMI was below 18.50. Students whose BMI was between 18.50 and 24.99 had a normal weight, the ones whose BMI was between 25 and 29.99 were with overweight and students whose BMI was higher than or equal to 30 were obese [11].

Physical activity was assessed using the short version of International Physical Activity Questionnaire (IPAQ). Students' physical activity was assessed according to its intensity (low, moderate and high) during the 7 days which preceded the survey based on its weekly frequency and its daily duration [12].

Entry and processing of data were performed using the software Epi-Info 7.1.2. The measures of central tendency of the quantitative variables were described by calculating averages and their standard deviation. As regards qualitative variables, ratios and proportions were determined. $\mathrm{Khi}^{2}$ test was used to compare ratios and proportions; and difference was considered as significant if $p$-value $<0.05$.

\section{Ethical and Professional Considerations}

Data collection had been authorized by the Regional Director of Secondary, Technical and Vocational Training for Borgou. It had been also authorized by the Heads of secondary schools. Students' free and informed consent had been obtained before any inclusion and involvement. Data confidentiality was maintained.

\section{Results}

\subsection{Sociodemographic Characteristics of Students Included in the Study}

In total, 730 students were involved in the study, including 377 male (51.6\%) and 353 female (48.4\%) i.e. a sex ratio of 1.1. Mean age for students was $16.3 \pm$ 2.9 years with extremes from 9 to 25 years. Students under 18 years of age were the predominant age group with a ratio of $78.22 \%$. Students whose socioeconomic status was average were predominant (55.1\%). Table 1 shows the distribution of students according to their sociodemographic characteristics.

\subsection{Prevalence of Overweight and Obesity among the Population of Respondent Students}

Prevalence of overweight/obesity was $16.2 \%$, including $12.5 \%$ of overweight and $3.7 \%$ of obesity. 
Table 1. Distribution of students included in the study according to sociodemographic characteristics and parents' characteristics $(\mathrm{N}=730)$.

\begin{tabular}{ccc}
\hline & Population size & $\%$ \\
\hline Sex & 377 & 51.6 \\
Male & 353 & 48.4 \\
\hline Female & & \\
\hline Age (years) & 571 & 78.2 \\
\hline$<18$ & 159 & 21.8 \\
$\geq 18$ & 183 & \\
\hline Type of school attended & 547 & 25.1 \\
\hline Private & & 74.9 \\
State-owned & 509 & 69.7 \\
\hline Parents' socioeconomic status & 221 & 30.3 \\
\hline Low/Average & & 34.5 \\
\hline High/Very high & 252 & 65.5 \\
\hline Family history of obesity & 478 & \\
\hline Yes & & \\
No & & \\
\hline
\end{tabular}

\subsection{Relationship between Overweight and Family \& Sociodemographic Characteristics of Students}

Students' sex and family history of obesity were statistically associated with the occurrence of overweight respectively with $p=0.0001$ and $p=0.0002$. Female students ran 2.7 times the risk of being with overweight. Table 2 shows the distribution of students according to their family and sociodemographic characteristics, depending on the presence or not of overweight.

\subsection{Relationship between Obesity and Students' Family and Sociodemographic Characteristics}

Sex, type of school attended, parents' socioeconomic status and family history of obesity were statistically associated with occurrence of obesity respectively with $p=0.0018, p=0.0001, p=0.0008$ and $p=0.0001$. Table 3 shows the distribution of students according to their family and sociodemographic characteristics depending on the presence of obesity.

These two tables show that female gender, history of family obesity, excessive consumption of sugary drinks and low exercise levels are associated with overweight and obesity among high school and college students in Parakou.

\section{Discussion}

This study shows the real aspects of overweight and obesity in the secondary schools of the district of Parakou in 2017; it calls on authorities at all levels as well as students' parents on the urgent need to respond to those health concerns. In fact, the prevalences of overweight and obesity were respectively estimated at 
Table 2. Relationship between overweight and family and sociodemographic characteristics of students from secondary schools of Parakou in 2017.

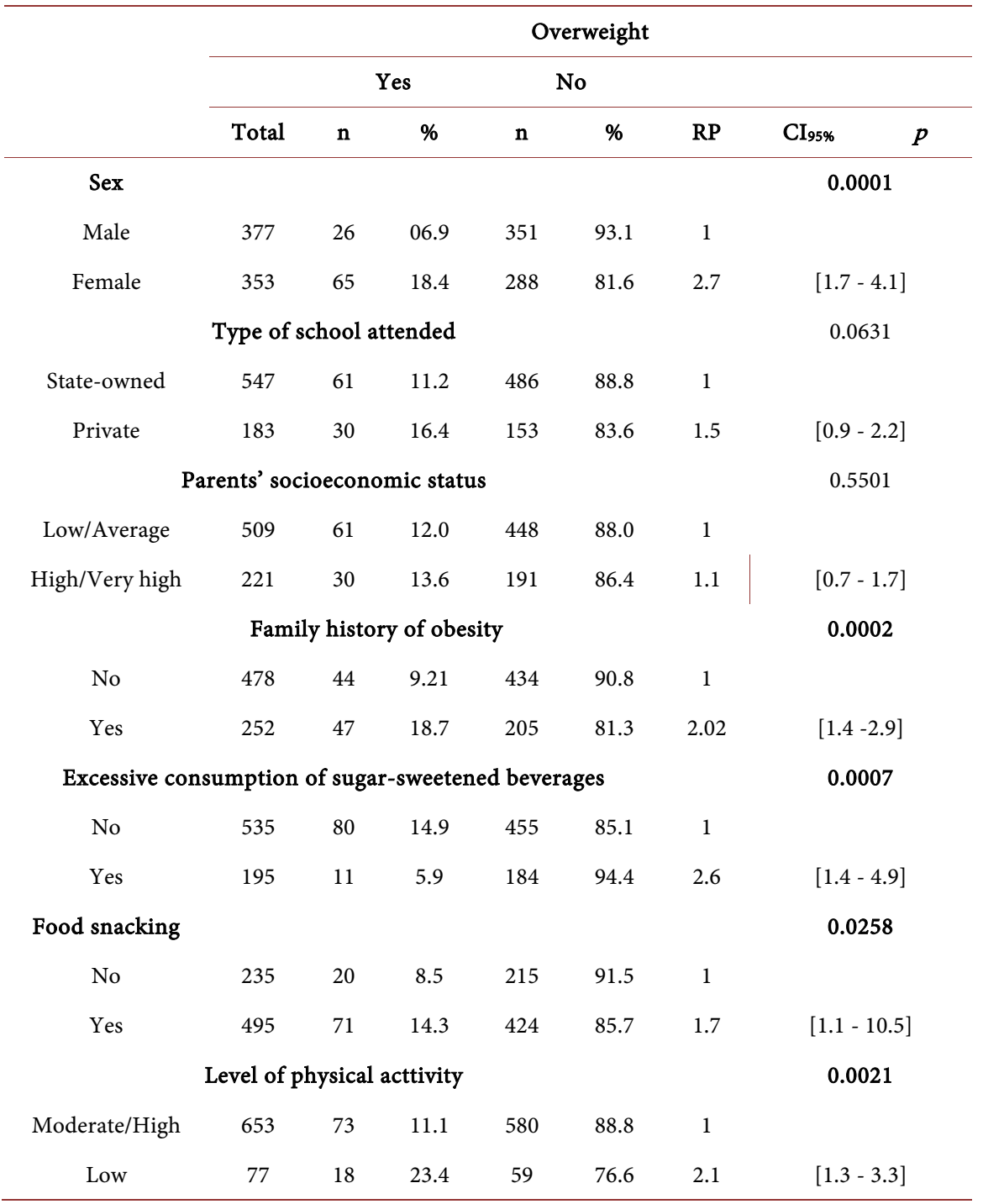

$12.5 \%$ and $3.7 \%$. Although they are relatively low compared to the ones of European and American countries, these prevalence rates must be substantially reduced. Moreover, emergency actions should be undertaken to stem and contain the ailment.

Overweight and obesity were significantly associated with sex. Female students were nearly three times at risk for overweight and nearly four times at risk for obesity. In most areas of Benin, most of time overweight and obesity affect mainly female subjects. This social trend noted arouses scientific curiosity and encourages to conduct a thorough investigation. Actually, female subjects are more likely to consume sweeter foods and adopt a more sedentary lifestyle; in addition, they are physically more inactive compared to men. This may explain why women are often mostly affected by excess weight than men in general worldwide. Some studies carried out by the Massachusetts Medical Society in the 
Table 3. Relationship between students and parents' sociodemographic characteristics and obesity.

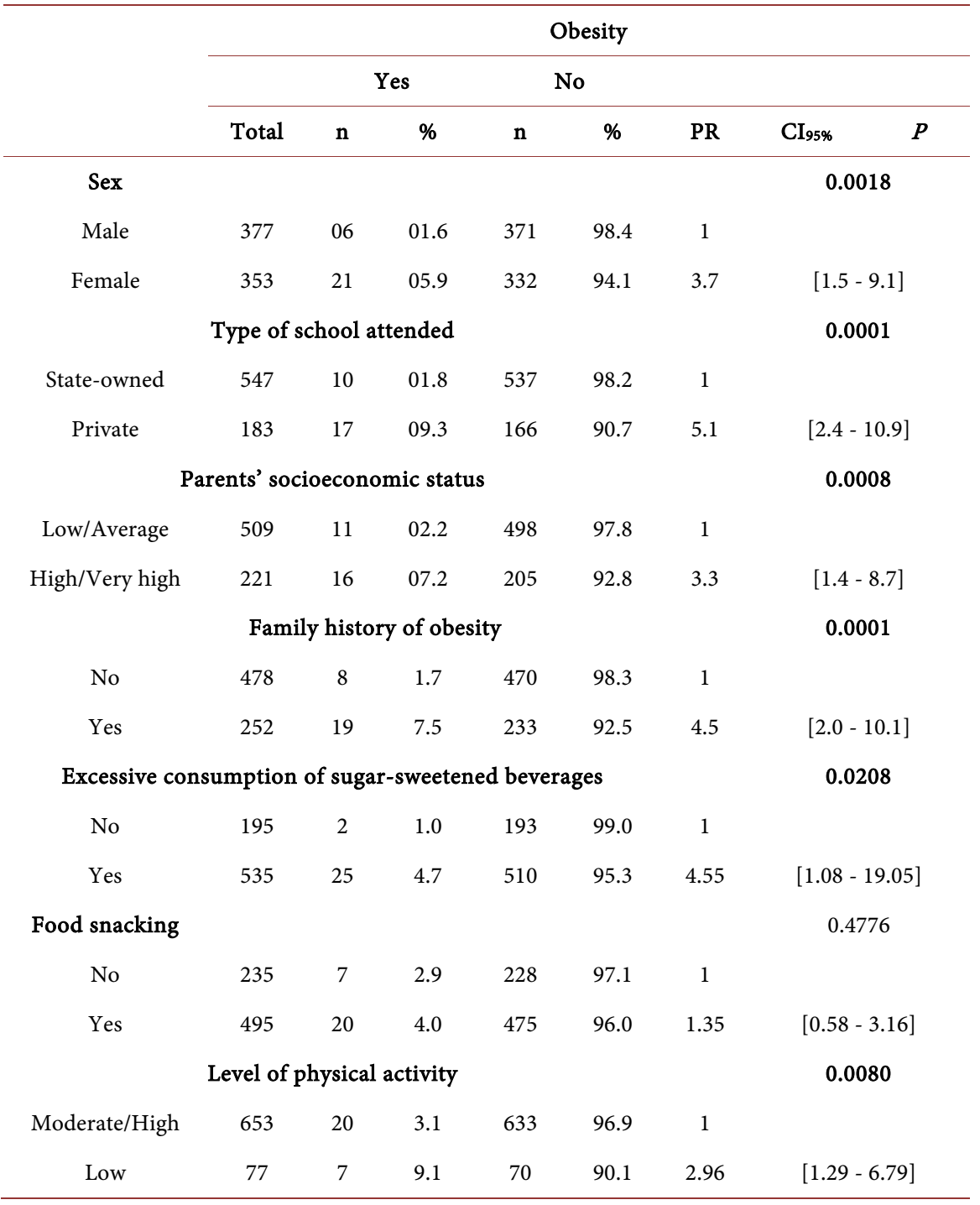

United States in 2017, by Faye et al. in Senegal in 2011, Lamri et al. in Morocco in 2016 and Yessouffou et al. in Benin in 2012 all reported the same observations [13] [14] [15] [16] [17].

Students whose parents have a high socioeconomic status are three times more exposed to obesity than students whose parents have a low socioeconomic status. But there was no relationship or association between overweight and socioeconomic status of students' parents. The risk for excess weight increases with socioeconomic status. Low socioeconomic status was a risk factor for excess weight in developed countries. However, in developing countries, rather it is high socioeconomic status that exposes to risk for excess weight [17]. Lokrou et al. in 2008 in Cote d'Ivoire, Regaieg et al. in 2014 in Tunisia and Kouakou et al. in Cote d'Ivoire in 2017 confirmed the negative influence of high socioeconomic status on excess weight [18] [19] [20]. In developing countries, the financial 
freedom of some wealthy parents facilitates over-nutrition among their children who most of the times lead a life without physical activity. Actually, parents with high socioeconomic status often make available to their children video games, pads and other play material without strenuous physical activity. In addition, they put means of transportation like motorcycles and cars at the disposal of their children, thus facilitating their physical inactivity. Moreover, globalization resulting in releasing information and advertising on refined foodstuffs are all elements that adversely influence low-resource countries where overweight and obesity are increasingly growing. That is the phenomenon of nutritional transition: people living even in rural areas and who previously adopted non obesogenic dietary pattern and lifestyle, change those natural behaviors to lead a "westernized life".

In this research work, the students enrolled in private schools were five times more exposed to obesity than those enrolled in government-owned schools. This is not surprising since parents with high socioeconomic status most often prefer to enroll their children in private schools. Faye et al made the same remark according to which a high ratio of children with obesity was enrolled in private schools in Dakar in 2011 [14]. However, in this study, the occurrence of overweight in schools was not associated with the private or public (government-owned) nature of the school. In Benin, students enrolled in private schools have in general parents wealthier than parents of students enrolled in government-owned schools. Therefore, this observation would be closely linked with the socioeconomic status of students' parents.

In this study, the excessive consumption of sugar-sweetened beverages was statistically associated with overweight and obesity, respectively with $p$-values of 0.0007 and 0.0208 . The role of nutritional factors in the occurrence of overweight and obesity has been reported by many authors [21] [22]. Kouéta et al. in Burkina Faso in 2011 and Makoutodé et al in Benin in 2017 had reported a similar result in their studies [23] [24]. As well, (food) snacking was statistically associated with overweight $(p=0.0258)$ but it was not statistically associated with obesity $(p=0.4776)$. There is a relatively partial discrepancy between this remark and literature data. For instance, food snacking between regular meals would also be involved in the occurrence of overweight [23] [24]. The absence of relationship noted between snacking between regular meals and obesity in $\mathrm{Pa}-$ rakou schools may be due to the fact that local students would not snack between meals to such a degree that they become obese because of snacking behavior. However, students with overweight who were used to practice snacking between regular meals are at risk of developing obesity if they do not give up that bad eating habit.

Besides, the low level of physical activity multiplied respectively by two and by nearly three the risk for overweight and obesity in the study. These results are in accordance with the ones of many other authors such as Kouéta et al. Zedini et al. in Tunisia in 2016, Ginoux et al. in France in 2006 [24] [25] [26]. As overweight and obesity are caused by a sustained positive energy balance between 
inputs and outputs, physical activity represents a key factor to negate that balance. The true relationship between obesity and physical activity is difficult to discern in cross-sectional studies. Physical inactivity had been seen in many subjects with obesity in this study; however, it is difficult for us to know for sure whether it is physical inactivity that caused obesity or if it is obesity that led student to a sedentary lifestyle. A cohort study on the role of physical activity in weight balance may help clarify that phenomenon.

\section{Conclusion}

In brief, female sex, high socioeconomic status, excessive intake of sugar-sweetened beverages, low level of physical activity were factors associated with overweight and obesity in the schools of Parakou in 2017. In the light of these results, everyone should change his behavior toward the different contributing factors. This will enable us to reverse the trajectory of overweight and obesity prevalence in the district of Parakou. It is therefore important to conduct an active fight through a prevention programme on the basis of the different factors identified, in order to improve the lifestyle of each student in the district. This will consist of developing physical activities at school and appropriate nutritional education.

\section{Conflicts of Interest}

The authors declare no conflicts of interest regarding the publication of this paper.

\section{References}

[1] FAO, FIDA and WFP (2013) The State of Food Insecurity in the World, 2012. Economic Growth Is Necessary But Not Sufficient to Accelerate the Reduction of Hunger and Malnutrition. FAO, Roma.

[2] Delisle, H. (2002) Fetal Programming of Chronic Diseases Associated with Nutrition. Cahiers Santé, 12, 56-63.

[3] Ben Slama, F., Skiri, H., Ben Romdhame, H., Zouari, B., Halayem, M.B. and Achour, N. (2005) Mothers' Perception of Child Obesity. Revue Maghrébine de Pédiatrie, 15, 181-186.

[4] Das, S.K., Chisti, M.J., Huq, S., Malek, M.A., Vanderlee, L., Salam, M.A., Ahmed, T., Faruque, A.S.G. and Al Mamun, A. (2013) Changing Trend of Overweight and Obesity and Their Associated Factors in an Urban Population of Bangladesh. Food and Nutrition Sciences, 4, 678-689. http://www.scirp.org/journal/fns https://doi.org/10.4236/fns.2013.46087

[5] Ijoma, U.N., Chime, P., Onyekonwu, C., Ezeala-Adikaibe, B.A., Orjioke, C., Anyim, O.B., Onodugo, O.D., Aneke, E., Nwatu, C.B., Young, E., Mbadiwe, N., Ekenze, O.S., Okoye, J.U., Abonyi, M., Ulasi, I.I., Mbah, A. and Onodugo, P.N. (2019) Factors Associated with Overweight and Obesity in an Urban Area of South East Nigeria. Food and Nutrition Sciences, 10, 735-749. http://www.scirp.org/journal/fns https://doi.org/10.4236/fns.2019.107054

[6] Kyallo, F., Makokha, A. and Mboganie Mwangi, A. (2013) Overweight and Obesity 
among Public and Private Primary School Children in Nairobi, Kenya. Health, 5, 85-90. https://doi.org/10.4236/health.2013.58A3012

[7] Agbohoui Houinato, O., Kpozehouen, A., Hounkpatin, B., Gbédji, K.Y., Robin, H., Mizéhoun-Adissoda, C., Guédou, F., Houinato, D.S. and Perrin, R.X. (2019) Prevalence and Factors Associated with Overweight and Obesity among Adolescents in Schools in Benin in 2016. Open Journal of Epidemiology, 9, 213-242.

http://www.scirp.org/journal/ojepi https://doi.org/10.4236/ojepi.2019.93018

[8] Schwartz, B., Woods, T., Liyanage, W. and Smith, D. (1991) A Simplified General Method for Cluster-Sample Surveys of Health in Developing Countries. World Health Statistics Quarterly, 44, 98-106.

[9] Kpozehouen, A., Glèlè Ahanhanzo, Y., Paraïso, M., Tchaniley, G., Aïssan, J., Degbey, C., et al. (2016) Prevalence and Factors Associated with Overweight and Obesity among Adolescents in the Schools of the District of Klouékanmè in Benin. Revue d Épidémiologie et de Santé Publique, 64, 8-14. https://doi.org/10.1016/j.respe.2016.06.303

[10] Khadilkar, V., Yadav, S., Agrawal, K.K., et al. (2015) Revised IAP Growth Charts for Height, Weight and Body Mass Index for 5-18 Year Old Indian Children. Indian Pediatrics, 52, 47-55. https://doi.org/10.1007/s13312-015-0566-5

[11] Cole, T.J., Bellizi, M.C., Flegal, K.M. and Dietz, W.H. (2000) Establishing a Standard Definition for Child Overweight and Obesity Worldwide: International Survey. British Medical Journal, 320, 1240-1243. https://doi.org/10.1136/bmj.320.7244.1240

[12] Guidelines for the Data Processing and Analysis of the International Physical Activity Questionnaire (IPAQ). Short and Long Forms, November 2005. https://www.ipaq.ki.se/scoring

[13] Massachusetts Medical Society (2017) Health Effects of Overweight and Obesity in 195 Countries over 25 Years. The New England Journal of Medicine, 377, 13-27. http://www.nejm.org/doi/full/10.1056/NEJMoa1614362\#article https://doi.org/10.1056/NEJMoa1614362

[14] Faye, J., Diop, M., Gati Ouonkoye, R., Seck, M., Mandengue, S.H., Mnengue, A., et al. (2011) Prevalence of Child and Teenage Obesity in Schools in Dakar. Bulletin de la Société de Pathologie Exotique, 104, 49-52.

https://doi.org/10.1007/s13149-010-0101-9

[15] Yessouffou, G., Attakpa, E., Baba-Moussa, F., Houhouignan, J.D., Baba-Moussa, L. and Sezan, A. (2012) Prevalence and Role of Lipids in the Onset of Obesity in Benin. International Journal of Biological and Chemical Sciences, 6, 1695-1702. https://doi.org/10.4314/ijbcs.v6i4.26

[16] Lamri, D., Loukili, A., Lamrioui, D. and Hassouni, T. (2016) Obesity, Relationship between Body Mass Index and Physical Activity among Adolescents Enrolled in the Schools of the City of Taza, Morocco. The American Journal of Innovative Research and Applied Science, 2, 120-127.

[17] Poulain, J.P. (2010) Sociology of Obesity: Master of Social Science Applied to Nutrition. 95 p. https://fr.slideshare.net/mobile/Poulain

[18] Lokrou, A. and Nioblé, G. (2008) Prevalence of Overweight and Obesity in the Schools of Côte d'Ivoire. Médecine des Maladies Métaboliques, 2, 303-304. https://doi.org/10.1016/S1957-2557(08)71687-0

[19] Regaieg, S., Charfi, N., Trabelsi, L., Kamoun, M., Feki, H., Yaich, S., et al. (2014) Prevalence and Risk Factors for Overweight and Obesity in a Population of Children Enrolled in Urban Schools of Sfax, Tunisia. Pan African Medical Journal, 17, 57. 
https://doi.org/10.11604/pamj.2014.17.57.3351

[20] Kouakou, A.Y.F., Kamagate, A. and Yapo, A.P. (2017) Prevalence of Obesity among the Youths in Côte d'Ivoire. European Scientific Journal, 13, 241-248.

https://doi.org/10.19044/esj.2016.v13n3p241

[21] Basdevant, A. (2006) Obesity: Origins and Consequences of an Epidemic. Comptes Rendus Biologie, 329, 562-569. https://doi.org/10.1016/j.crvi.2006.03.018

[22] Ciangura, C., Faucher, P. and Oppert, J.M. (2014) Physical Activity, Nutrition and Obesity. Nutrition Clinique et Métabolisme, 28, 279-286.

https://doi.org/10.1016/j.nupar.2014.08.001

[23] Makoutodé, A., Saïzonou, J., Glèlè-Ahanhanzo, Y., Sossa, C.J. and Agueh, V. (2017) Prevalence and Factors Associated with Excess Weight among Adolescents in a Small City of Benin. International Journal of Biological and Chemical Sciences, 11, 798-805. https://doi.org/10.4314/ijbcs.v11i2.21

[24] Kouéta, F., Dao, L., Dao, F., Djekompté, S., Diarra, Y., Kam, K.L. and Sawadogo, A. (2011) Factors Associated with Overweight and Obesity of Students in Ouagadougou (Burkina Faso). CA Santé, 21, 227-231. https://doi.org/10.1684/san.2011.0272

[25] Zedini, C., Limam, M., El Ghardallou, M., Mellouli, M., Sahouda, K., Bougmiza, I., et al. (2016) Prevalence of Excess Weight in Schools of the Rural Area of Hazoua (Tozeur). La Tunisie Médicale, 94, 298-304.

[26] Ginoux, C., Grousset, J., Mestari, S. and Ruiz, F. (2006) Prevalence of Obesity among Children and Adolescents Enrolled in the Schools of Seine Saint-Denis. Cairn International, 18, 389-404. https://doi.org/10.3917/spub.063.0389 